\title{
A Self-Administered Questionnaire to Measure Dependence on Cigarettes: The Cigarette Dependence Scale
}

\author{
Jean-François Etter*,', Jacques Le Houezec ${ }^{2}$ and Thomas V Perneger ${ }^{1,3}$ \\ 'Institute of Social and Preventive Medicine, University of Geneva, Switzerland; ${ }^{2}$ Pharmacia R\&D Consumer Healthcare, Helsingborg, Sweden; \\ ${ }^{3}$ Quality of Care Unit, Geneva University Hospitals, Switzerland
}

\begin{abstract}
A valid measure of dependence on cigarettes is a useful tool for clinicians and researchers. The aim of this study was to develop a new, self-administered measure of cigarette dependence, and to assess its validity. The content of the instrument was generated in qualitative surveys. A long version ( I 4 items) was tested on the internet in 3009 smokers. Subsamples provided retest data after I 8 days ( $n=578$ ), follow-up data after 45 days $(n=990)$ and saliva cotinine $(n=105)$. The study resulted in a 12 -item scale labelled the Cigarette Dependence Scale (CDS- I2), and in a 5-item version of this scale (CDS-5). Except for tolerance, CDS- I 2 covers the main components of DSM-IV and ICD-IO definitions of dependence: compulsion, withdrawal symptoms, loss of control, time allocation, neglect of other activities, and persistence despite harm. CDS-5 has similar measurement properties but less comprehensive content. Both scales had a high test-retest reliability $(r \geqslant 0.83)$, and a high internal consistency (Cronbach's $\alpha \geqslant 0.84)$. CDS- 12 scores were higher in daily smokers than in occasional smokers (+1.3SD units), and were associated with the strength of the urge to smoke during the last quit attempt $\left(R^{2} \geqslant 0.25\right)$, and with saliva cotinine $\left(R^{2} \geqslant 0.17\right)$. CDS- 12 and CDS-5 scores decreased in daily smokers who switched to occasional smoking at I8-day retest. Dependence scores did not predict smoking abstinence at follow-up. In conclusion, CDS- I 2 and CDS-5 are reliable measures of cigarette dependence which fulfill several criteria of content validity and construct validity and are sensitive to change over time.

Neuropsychopharmacology (2003) 28, 359-370. doi: I 0.1038/sj.npp. 1300030
\end{abstract}

Keywords: tobacco use disorder; nicotine dependence; smoking; validation studies; epidemiologic measurements; internet

\section{INTRODUCTION}

A valid measure of dependence on cigarettes is needed both for effective preventive care and for research purposes. There are two traditions of measurement in clinical sciences: the clinimetric tradition and the psychometric tradition (Wright and Feinstein, 1992). The clinimetric approach relies on doctors' expertise and patients' experience to define a set of signs and symptoms that are deemed relevant for a given disease. The logic of a clinimetric instrument is grounded in medical opinion, and the items forming the instrument can be quite disparate, as long as they are clinically connected. In contrast, the psychometric approach seeks to identify a correlated set of items that reflect, as much as possible, an unobserved latent variable. The logic of a psychometric instrument relies heavily on statistical properties, such as reliability and validity.

Thus far, addiction to cigarettes has been assessed by clinimetric scales only. The most frequently used instruments are the Fagerström Tolerance Questionnaire (FTQ),

\footnotetext{
*Correspondence: J-F Etter, Institute of Social and Preventive Medicine, University of Geneva, CMU, Case Postale, CH-1211 Geneva 4, Switzerland, Tel: +4l 2270259 19, Fax: +4l 2270259 12, E-mail: Jean-Francois.Etter@imsp.unige.ch. Internet: www.stop-tabac.ch Received 20 February 2002; revised 10 June 2002; accepted 10 July 2002
}

published 25 years ago (Fagerström, 1978), a shorter version of this test, the Fagerström Test for Nicotine Dependence (FTND) (Heatherton et al, 1991), and a modified version of this test for adolescents (Prokhorov et $a l, 2000$ ). These tests have several limitations. First, they fail to include important aspects of dependence, as defined in DSM-IV and ICD-10 (Etter et al, 1999; Moolchan et al, 2002). Several items of FTND are difficult to apply to moderate smokers, and the internal consistency of FTQ and FTND is low (Etter et al, 1999; Heatherton et al, 1991; Lichtenstein and Mermelstein, 1986; Pomerleau et al, 1990). Another published scale is based on the DSM definition of dependence (Kawakami et al, 1999), and two other scales also based on DSM were not published in peer-reviewed journals (Covey and Elmer, 1999; Saul Shiffman, personal communication). One scale is intended for adolescents only (DiFranza et al, 2002).

Other clinimetric measures are DSM-IV and ICD-10 diagnoses of tobacco dependence, which can be established through clinical interviews such as the Composite International Diagnostic Interview (CIDI) (Ustun et al, 1997), the Diagnostic Interview Schedule (DIS) (Johnson et al, 1996) or the MINI interview (Nezelof et al, 2001). These interviews must be administered by trained personnel, which is costly, and they identify only the presence but not the intensity of dependence. 
In this study, we used a psychometric approach to develop a short, valid, self-administered, continuous measure of addiction to cigarettes, developed according to standard psychometric methods, and covering DSM-IV and ICD-10 criteria of dependence (Colby et al, 2000).

\section{METHODS}

\section{Scale Development}

We used a systematic approach to the development of the scale (Jackson, 1970; Streiner and Norman, 1995). First, we conducted two surveys, one by mail and the other on the internet, to collect qualitative data on dependence on cigarettes. We sent a questionnaire by mail in 1999 to a random sample of 2000 people (age range 18-70 years), drawn from the official registry of residents of Geneva, Switzerland. Only current and former smokers were invited to take part in the survey. The main purpose of this survey was to assess attitudes towards nicotine replacement therapy (Etter and Perneger, 2001a), but participants were also asked to give written answers to the following question: 'In your opinion, what signs indicate that smokers are dependent on cigarettes?' The same question was posted on the Stop-tabac.ch website between October 1999 and April 2000. We classified answers to both surveys according to their content and counted the number of citations in each category (Table 1).

Then, we used these qualitative data and the scientific literature to write 153 items (in French), following recommended rules for item writing (Nunnally and Bernstein, 1994; Streiner and Norman, 1995). We wrote items covering each dimension of DSM-IV and ICD-10 definitions of tobacco dependence and the main categories in qualitative data (American Psychiatric Association, 1994; World Health Organization, 1992). This 153-item questionnaire was split into two parts and tested in 506 and 606 smokers recruited on the internet, on www.stop-tabac.ch. At this stage, we deleted 39 items that had a high proportion of missing or 'Don't know' answers, important floor or ceiling effects, or weak associations with other indicators of dependence (cigarettes per day, minutes to first cigarette

Table I Answers to the Question: 'In your opinion, what signs indicate that smokers are dependent on cigarettes?', given by 384 Smokers and Ex-smokers Recruited by Mail, and 145 Smokers and Ex-smokers Recruited on the Internet in 1999-2000

\begin{tabular}{|c|c|c|}
\hline & \multicolumn{2}{|c|}{ No. of comments } \\
\hline & Mail survey & Internet survey \\
\hline $\begin{array}{l}\text { Feeling nervous, irritable, anxious, stressed, impatient, aggressive, in a bad } \\
\text { mood when lacking cigarettes }\end{array}$ & 119 & 12 \\
\hline $\begin{array}{l}\text { Compulsive need to smoke, always needs to smoke, inability to resist } \\
\text { cigarettes, urge to smoke, physical need to smoke, fear of experiencing the } \\
\text { urge to smoke, impossible not to smoke }\end{array}$ & 118 & 49 \\
\hline $\begin{array}{l}\text { Smoke at precise times of the day, in precise situations, stereotypic use, } \\
\text { automatic smoking, habit, ritual, smokes at regular intervals }\end{array}$ & 109 & 23 \\
\hline $\begin{array}{l}\text { Making stocks of cigarettes, always taking care of having enough cigarettes, } \\
\text { borrowing cigarettes, always carrying cigarettes with him/her }\end{array}$ & 46 & 19 \\
\hline Smoking after the meal & 20 & 0 \\
\hline Smoking when stressed or when feeling nervous & 20 & 3 \\
\hline $\begin{array}{l}\text { Frequency of smoking, number of cigarettes per day, chain smoking, smoking } \\
\text { more and more, smoking too much, more than } \times \text { cigarettes }\end{array}$ & 19 & 18 \\
\hline Smoking as soon as waking up, urge to smoke in the morning & 19 & 14 \\
\hline Smoking with other smokers, when someone lights a cigarette & 18 & 0 \\
\hline Feeling pleasure when smokes, cigarettes are relaxing & 13 & 10 \\
\hline $\begin{array}{l}\text { Going out at night or making kilometers just to buy cigarettes, needing } \\
\text { cigarettes at any price, at any time }\end{array}$ & 12 & 12 \\
\hline Smoking when drinking alcohol & II & 0 \\
\hline Smoking to avoid boredom, or when waiting for someone & 8 & 5 \\
\hline Smoking when drinking a coffee & 8 & 0 \\
\hline $\begin{array}{l}\text { Avoiding activities and places because smoking is prohibited, interrupting } \\
\text { one's activity to smoke }\end{array}$ & 7 & 12 \\
\hline Difficulty concentrating when deprived & 6 & 2 \\
\hline Smoking in all circumstances and situations & 5 & 3 \\
\hline $\begin{array}{l}\text { Smoking even where it is prohibited, in any situation, or even in the presence } \\
\text { of nonsmokers, or smoking when ill, denying the risks }\end{array}$ & 4 & 18 \\
\hline Difficult to quit smoking & 4 & 0 \\
\hline Tremor & 4 & 0 \\
\hline Smoking in spite of the danger, costs and drawbacks of cigarettes & 3 & 6 \\
\hline Cough & 3 & 0 \\
\hline Being aggressive and intolerant against nonsmokers & 0 & 4 \\
\hline Other & 0 & 23 \\
\hline Total & 576 & 233 \\
\hline
\end{tabular}


of the day, 0-100 scale of self-perceived dependence, occasional $v s$ daily smoking, self-perceived difficulty to quit, and the strength of the urge to smoke during the last quit attempt). We retained 114 items for the next phase. These items are available at http://www.stop-tabac.ch/fr/ q-addic-round2-23.html.

\section{Main Survey}

We conducted a survey on the internet to test the psychometric properties of these 114 items, to construct shorter composite scales, and to assess the validity of these scales. Data were collected between September 2000 and June 2001. An invitation to fill the survey was sent by e-mail to 5000 smokers who participated in the 'Stop-tabac.ch' smoking cessation program (Etter and Perneger, 2001b). A link to the questionnaire was also posted on several pages of this site. The site was visited by 95000 people during the data collection period. Only current cigarette smokers were invited to answer the questionnaire.

\section{Questionnaire Content}

Participants answered 108 of the 114 questions on 5-point Likert scales ranging from 'totally disagree' to 'fully agree' (Table 2). A sixth response option labelled 'I don't know/ Not applicable' was coded as a missing value. Other items intended to measure dependence included a $0-100$ rating of one's level of dependence (Table 2); a 0-100 rating of the strength of the urge to smoke during the last quit attempt, with two anchors (Absolutely no need to smoke $=0$ and ' $A$ constant, urgent and uncontrollable need to smoke $=100$ '); the number of cigarettes smoked per day; the number of minutes between waking up and smoking the first cigarette of the day; whether quitting smoking would be difficult (five response options, from 'very easy' to 'impossible'); and the Fagerström test for nicotine dependence (Heatherton et al, 1991).

Additional questions probed whether participants had ever smoked 100 cigarettes in their lifetime (which is the criterion recommended by WHO to identify ever smokers) (World Health Organization, 1996); whether they smoked every day, occasionally (not daily) or never; whether it was likely that they would have quit smoking in 1 year from now (six response options, from 'Yes, it is very likely' to 'No, it is highly unlikely'); and the level of motivation to quit smoking (three response options: not in the next six months, in the next six months and in the next 30 days) (Prochaska et al, 1992). The questionnaire also covered age and sex. We recorded the date when the questionnaire was answered and the computer number of each participant to identify duplicate records. Participants who agreed to take part in a follow-up survey indicated their first name and e-mail address.

\section{Retest}

Participants who agreed were invited by e-mail to answer the same questionnaire a second time, 2 weeks after the baseline survey. To assess reliability, we computed intraclass correlation coefficients for each item and scale (Streiner and Norman, 1995) among participants who were smokers on both occasions and who answered the retest questionnaire within 15-31 days after the baseline survey.

\section{Follow-up}

To assess whether intended measures of dependence predicted smoking cessation, participants who agreed were invited by e-mail 40 days after baseline to answer the following question by 'yes' or 'no': 'Did you smoke tobacco during the past 7 days (even one puff of cigarette, cigar, pipe, etc)?' The criterion of 1 week of abstinence was recommended by a recent guideline to assess the outcome of smoking cessation treatments (Fiore et al, 2000).

\section{Saliva Cotinine}

Volunteers who provided a postal address received a plastic vial for analysis of saliva cotinine (Salivette, Sarstedt, Nümbrecht, Germany). Cotinine, a major metabolite of nicotine, has a half-life of $20 \mathrm{~h}$ in smokers (PerezStable et al, 1995), and is stable in saliva when mailed or stored at room temperature during several days (Etter et al, 2000; Foulds et al, 1994; Greeley et al, 1992). The saliva samples were frozen at $-20^{\circ} \mathrm{C}$ upon receipt and sent for cotinine analysis to ABS Laboratories (Dr Feyerabend, London). Saliva cotinine level was determined by gas-liquid chromatography (Feyerabend and Russell, 1990). Because of budget limitations, we sent vials to 300 participants only.

\section{Factor Structure}

We applied factor analysis to assess the factorial structure of the data. To assess whether the data were uni- or multifactorial, we applied Velicer's MAP test, Horn's parallel analysis, the criterion of eigenvalue $>1$, and criteria of interpretability and content validity (Horn, 1965; O’Connor, 2000; Velicer, 1976).

\section{Content Validity and Internal Consistency}

To assess content validity, we compared the content of the final scale to the categories in qualitative data, and to DSMIV and ICD-10 definitions of dependence (Table 3). We assessed whether internal consistency coefficients (Cronbach's $\alpha$ ) of the scales exceeded 0.7, as recommended (Nunnally and Bernstein, 1994).

\section{Construct Validity}

We tested the following hypotheses to assess construct validity:

1. Dependence would be stronger in daily smokers than in occasional smokers.

Dependence measures would be associated with:

2. the number of cigarettes smoked per day;

3. the Fagerström test for nicotine dependence (Heatherton et al, 1991);

4. a $0-100$ rating of the urge to smoke during the last quit attempt;

5. the level of saliva cotinine. 
Table 2 Characteristics of Items and Scales, and Tests of Construct Validity

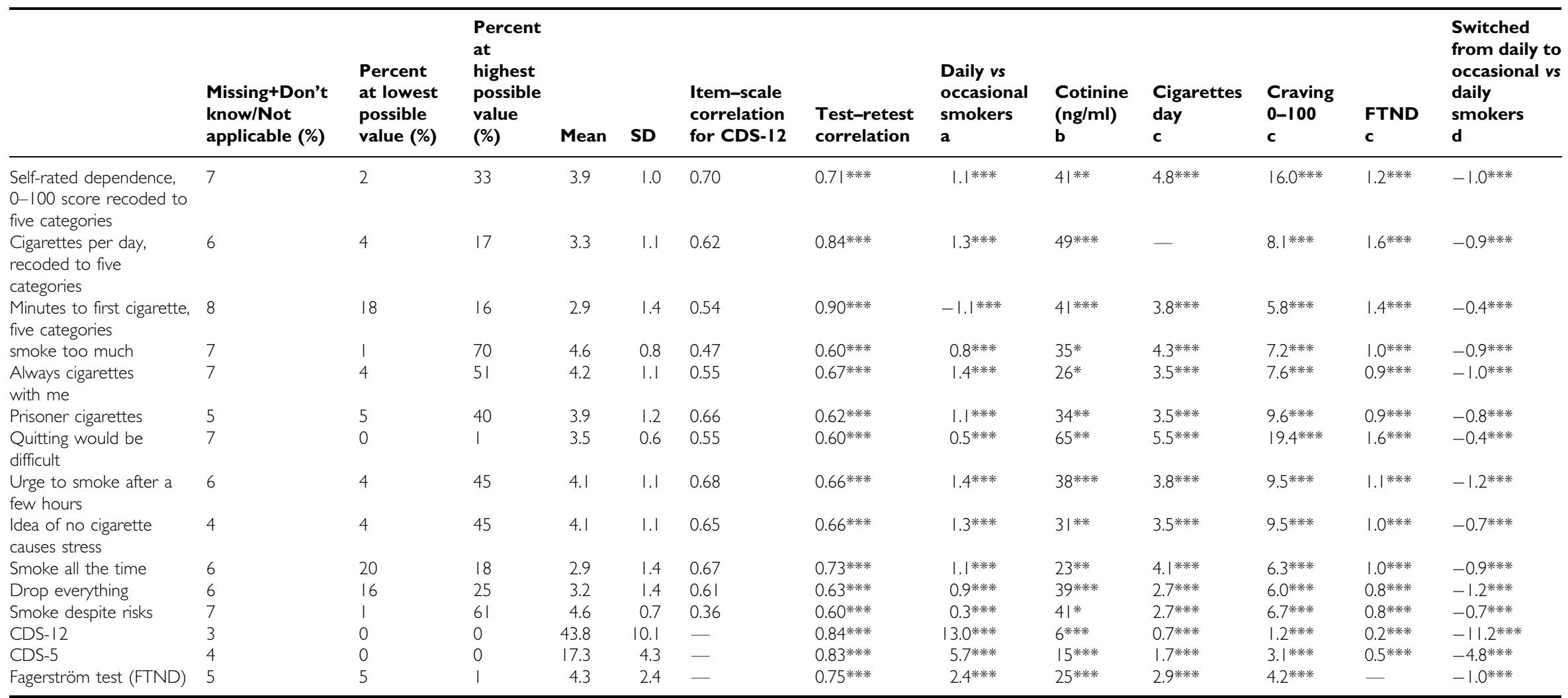

(a) Difference between daily and occasional smokers; (b) change in saliva cotinine levels ( $\mathrm{ng} / \mathrm{ml})$ per point in measures of tobacco dependence, from linear regression models; (c) change in cigarette/day, craving scores or FTND scores, per point in measures of tobacco dependence, from linear regression models; (d) difference in change over time between those who switched from daily to occasional smoking between baseline and cigarettes/day retest and those who remained daily smokers. ${ }^{p} \leqslant \leqslant 0.05 ; * * 0 \leqslant 0.01 ; * * * 0 \leqslant 0.001$. 
Table 3 Items Classified According to DSM-IV and ICD-IO Categories of Dependence

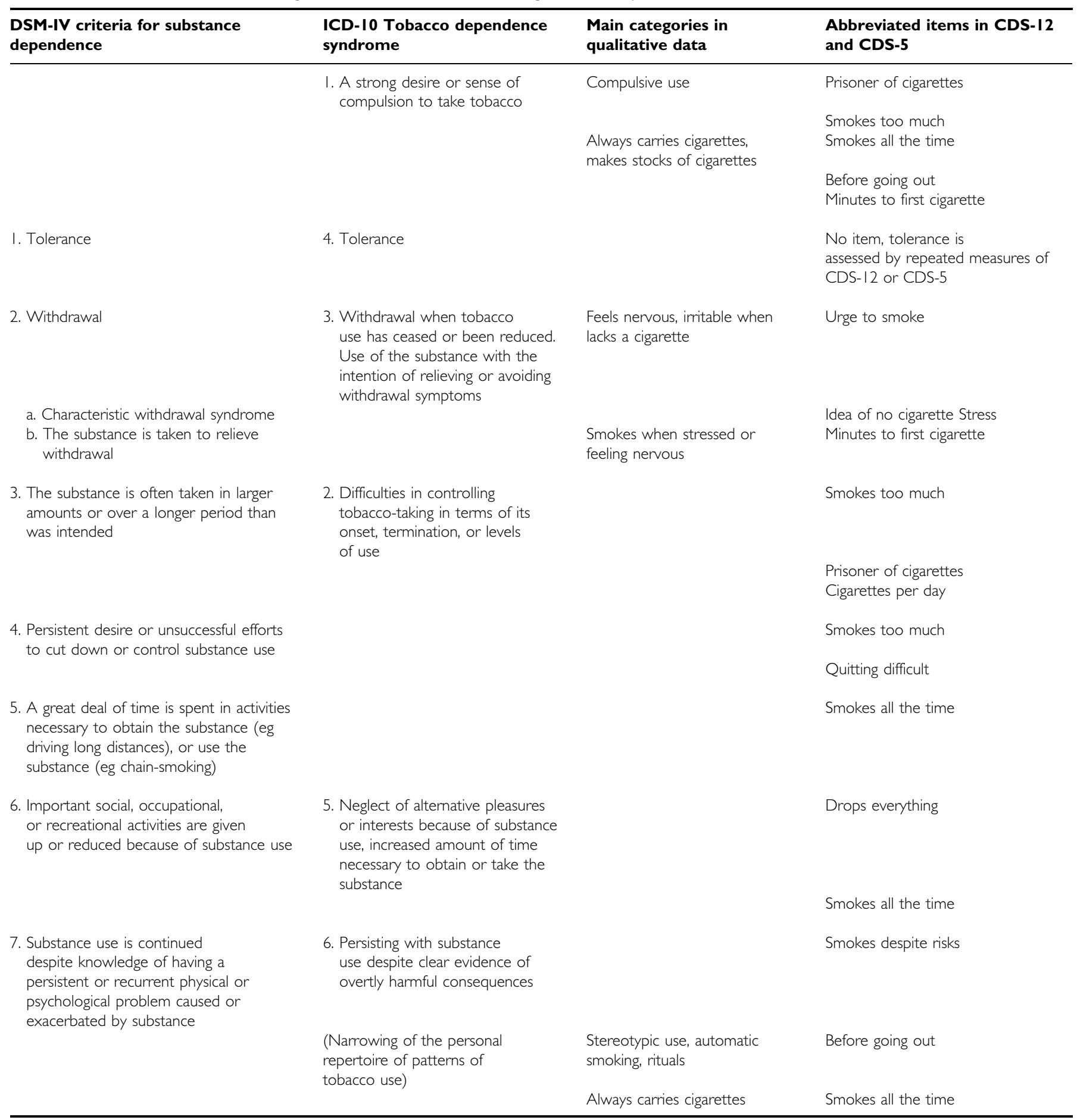

\section{Sensitivity to Change}

To assess whether intended measures of dependence were sensitive to change over time, we computed differences between baseline and retest for each indicator of dependence and for each participant. Then, we compared baseline-retest change scores in people who switched from daily to occasional smoking between baseline and retest $(n=31)$ and in those who remained daily smokers $(n=664)$.

\section{Development of Multi-item Scales}

To reduce the initial set of 114 items, we first determined the number of factors to retain. Then, we eliminated items that had the highest proportions of missing and 'Don't know' answers, important floor or ceiling effects, low test-retest correlations, a low loading on the main factor and weak performances on tests of construct validity. Next, we compared items that were variations of the same idea and retained only the items that performed best on tests of validity. 
When the set of items was finalized, we constructed a 12item composite scale by averaging the remaining items. We retained at least one item from each dimension of DSM-IV and ICD-10 definitions of tobacco dependence and for each of the main categories in qualitative data. We also developed a 5 -item version of the scale, for use when a short scale is preferred. We verified that the final scales were unidimensional in factor analysis.

\section{Age}

Tobacco dependence may differ in teenage and adult smokers (DiFranza et al, 2002; McNeill et al, 1989; Shadel et al, 2000). Thus, we assessed whether the characteristics of the scales were maintained in smokers aged 12-19 $(n=298)$, comparing them with smokers aged 20-74 $(n=2594)$.

\section{Statistical Analyses}

We used univariate linear regression models to assess associations between addiction items and scales (indepen- dent variables) and continuous dependent variables, and $t$ tests to assess associations between addiction items and scales and dichotomous dependent variables.

We used interaction terms from ANOVA models to compare the strength of associations between CDS-12 and external variables in teenage smokers and adult smokers.

To assess whether the differences between test-retest correlation coefficients $(r)$ of CDS-12, CDS-5 and FTND were statistically significant, we used Fisher's $z$ transformation, where $z(r)=(1 / 2) \ln ((1+r) /(1-r))$. When comparing correlation coefficients $r 1$ and $r 2$, a test statistic $z$ with a normal distribution is $z=(z(r 1)-z(r 2)) /$ $\sqrt{1 /(n 1-3)+1 /(n 2-3)}$. Differences are statistically significant if $z>1.96$ (Dawson-Saunders and Trapp, 1994).

\section{Translation into English}

We conducted a rigorous translation of the instrument into English to provide researchers and clinicians with a valid translation of the scales (English version, Table 4; French version, Table 5). First, four independent translations were

Table 4 The Cigarette Dependence Scale, English-Language Version

\begin{tabular}{|c|c|c|}
\hline Questions & Response options & Recoding \\
\hline $\begin{array}{l}\text { * I. Please rate your addiction to cigarettes on a scale of 0-100 } \\
\text { I am NOT addicted to cigarettes at all }=0 \\
\text { I am extremely addicted to cigarettes }=100\end{array}$ & Addiction & $\begin{array}{l}0-20=1 \\
21-40=2 \\
4 I-60=3 \\
6 I-80=4 \\
8 I-100=5\end{array}$ \\
\hline * 2. On average, how many cigarettes do you smoke per day? & Cigarette/day & $\begin{array}{l}0-5=1 \\
6-10=2 \\
11-20=3 \\
21-29=4 \\
30+=5\end{array}$ \\
\hline * 3. Usually, how soon after waking up do you smoke your first cigarette? & Minutes & $\begin{array}{l}0-5=5 \\
6-15=4 \\
16-30=3 \\
31-60=2 \\
61+=1\end{array}$ \\
\hline * 4. For you, quitting smoking for good would be: & $\begin{array}{l}\text { Impossible }=5 \\
\text { Very difficult }=4 \\
\text { Fairly difficult }=3 \\
\text { Fairly easy }=2 \\
\text { Very easy }=1\end{array}$ & No recoding \\
\hline \multicolumn{3}{|l|}{ Please indicate whether you agree with each of the following statements: } \\
\hline * 5. After a few hours without smoking, I feel an irresistible urge to smoke & $\begin{array}{l}\text { Totally disagree }=1 \\
\text { Somewhat disagree }=2 \\
\text { Neither agree nor disagree }=3 \\
\text { Somewhat agree }=4 \\
\text { Fully agree }=5\end{array}$ & \\
\hline $\begin{array}{l}\text { 6. The idea of not having any cigarettes causes me stress } \\
\text { 7. Before going out, I always make sure that I have cigarettes with me } \\
\text { 8. I am a prisoner of cigarettes } \\
\text { 9. I smoke too much } \\
\text { 10. Sometimes I drop everything to go out and buy cigarettes } \\
\text { II. I smoke all the time } \\
\text { 12. I smoke despite the risks to my health }\end{array}$ & $\begin{array}{l}\text { As item no. } 5 \\
\text { As item no. } 5 \\
\text { As item no. } 5 \\
\text { As item no. } 5 \\
\text { As item no. } 5 \\
\text { As item no. } 5 \\
\text { As item no. } 5\end{array}$ & . \\
\hline $\begin{array}{l}\text { CDS-12 } \\
\text { CDS-5 (items marked } * \text { ) }\end{array}$ & & $\begin{array}{l}\text { Sum of items } 1-12 \\
\text { Sum of items } 1-5\end{array}$ \\
\hline
\end{tabular}


Table 5 The Cigarette Dependence Scale, French Language Version

\begin{tabular}{|c|c|c|}
\hline Questions & Options de réponse & Recodage \\
\hline $\begin{array}{l}\text { * I. Indiquez par un chiffre entre } 0 \text { et } 100 \text { quel est votre } \\
\text { degré de dépendance des cigarettes: } \\
\text { Je NE suis absolument PAS dépendant des cigarettes }=0 \\
\text { Je suis extrêmement dépendant des cigarettes }=100\end{array}$ & Dépendance & $\begin{array}{l}0-20=1 \\
21-40=2 \\
41-60=3 \\
61-80=4 \\
81-100=5\end{array}$ \\
\hline * 2. Combien de cigarettes fumez-vous par jour, en moyenne? & Cigarettes/jour & $\begin{array}{l}0-5=1 \\
6-10=2 \\
11-20=3 \\
21-29=4 \\
30+=5\end{array}$ \\
\hline $\begin{array}{l}\text { * 3. D'habitude, combien de temps apres votre réveil } \\
\text { fumez-vous votre première cigarette? }\end{array}$ & Minutes & $\begin{array}{l}0-5=5 \\
6-15=4 \\
16-30=3 \\
31-60=2 \\
61+=1\end{array}$ \\
\hline * 4. Pour vous, arrêter définitivement de fumer serait: & $\begin{array}{l}\text { Impossible }=5 \\
\text { Très difficile }=4 \\
\text { Plutôt difficile }=3 \\
\text { Plutôt facile }=2 \\
\text { Très facile }=1\end{array}$ & Pas de recodage \\
\hline \multicolumn{3}{|l|}{$\begin{array}{l}\text { Veuillez indiquer si vous êtes d'accord avec } \\
\text { chacune des affirmations suivantes: }\end{array}$} \\
\hline $\begin{array}{l}\text { * 5. Après quelques heures passées sans fumer, je ressens le besoin } \\
\text { irrésistible de fumer }\end{array}$ & $\begin{array}{l}\text { Pas du tout } d^{\prime} \text { accord }=1 \\
\text { Plutôt pas } d^{\prime} \text { accord }=2 \\
\text { Plus ou moins } d^{\prime} \text { accord }=3 \\
\text { Plutôt d'accord }=4 \\
\text { Tout à fait d'accord }=5\end{array}$ & Pas de recodage \\
\hline $\begin{array}{l}\text { 6. Je suis stressé à l'idée de manquer de cigarettes } \\
\text { 7. Avant de sortir, je m'assure toujours que j'ai des cigarettes sur moi } \\
\text { 8. Je suis prisonnier des cigarettes } \\
\text { 9. Je fume trop } \\
\text { 10. II m'arrive de tout laisser tomber pour aller acheter des cigarettes } \\
\text { 11. Je fume tout le temps } \\
\text { 12. Je fume malgré les risques que cela entraîne pour ma santé }\end{array}$ & $\begin{array}{l}\text { comme item no. } 5 \\
\text { comme item no. } 5 \\
\text { comme item no. } 5 \\
\text { comme item no. } 5 \\
\text { comme item no. } 5 \\
\text { comme item no. } 5 \\
\text { comme item no. } 5\end{array}$ & \\
\hline $\begin{array}{l}\text { CDS-12 } \\
\text { CDS-5 (questions marquées *) }\end{array}$ & & $\begin{array}{l}\text { Somme items } 1-12 \\
\text { Somme items } 1-5\end{array}$ \\
\hline
\end{tabular}

made by a professional translator whose first language was English and by each author. On the basis of these translations, we produced a consensus version, which was tested by people whose mother tongue was English, recruited through the internet. First, 166 people chose their preferred formulation among alternative translations of problematic items and suggested alternative formulations. Next, 73 current smokers answered the final version of the translated questionnaire.

\section{RESULTS}

\section{Preliminary Surveys}

In the mail survey, we collected 494 questionnaires from smokers and ex-smokers (25\% of 2000), and 384 people (78\% of 494) contributed 576 statements on cigarette dependence. In the internet survey, 145 smokers and ex- smokers contributed 233 statements on cigarette dependence (Table 1).

\section{Participation in the Main Survey}

The raw baseline database included 3653 records. We deleted 38 empty records, 179 duplicate records, 103 records of people who had smoked fewer than 100 cigarettes in their lifetime, 63 records of people who gave obviously incorrect answers ( $\geqslant 150$ cigarettes/day, $>1000 \mathrm{~min}$ before the first cigarette of the day, age $<5$ years), and 261 records of ex-smokers. The analyses were based on the remaining 3009 participants, and included 2876 daily smokers (96\%), and 124 occasional smokers (4\%). Participants who indicated a postal address $(n=807,27 \%)$ came from France (56\%), Switzerland (28\%), Belgium (7\%), Canada (3\%), and other countries (6\%). Participants were on average 32 years old (range $12-74$ ) and $47 \%$ were men. Of these, $13 \%$ had no 
intention to quit smoking in the next 6 months, $46 \%$ seriously considered quitting in the next 6 months, and $41 \%$ had decided to quit in the next 30 days. A total of $49 \%$ had made a 24 -h quit attempt in the previous year.

\section{Item Selection}

We eliminated items with high proportions of missing and 'Don't know/Not applicable' answers and items that performed poorly on validity tests. Then, we compared items that were variations of the same idea and retained only items that performed best on validity tests. Finally, we retained 12 items because models with more items did not add to the performance of the scale, and because 12 items were sufficient to cover DSM-IV and ICD-10 definitions of dependence. Factor analysis indicated that only one factor was present in the final versions of CDS-12 and CDS-5; this factor explained $45 \%$ of total variance in CDS- 12 and $55 \%$ in CDS-5.

\section{Content Validity}

Except for tolerance, all other components of DSM-IV and ICD-10 definitions of dependence, and the most frequent categories in qualitative data were covered by at least one item in CDS-12. Items that measured tolerance (eg 'I have to smoke more and more cigarettes to obtain the same effect', 'Smoking a cigarette has fewer and fewer effects on me', 'I smoke more and more cigarettes') performed poorly and were not retained. Similarly, items on feeling nervous, irritable, anxious, or in a bad mood when lacking cigarettes performed poorly on validation tests and were not retained.

Items retained in CDS-5 did not cover all DSM-IV and ICD-10 criteria of dependence, but otherwise CDS-5 performed as well on validity tests as CDS-12.

\section{Characteristics of Items and Scales}

Retained items and scales had few missing and 'Don't know/ Not applicable' answers. Three items had proportions of 'Fully agree' above $50 \%$. CDS- 12 and CDS-5 were slightly skewed towards higher values (skewness $=-0.98$ and -0.74 , respectively). For CDS-12, the observed range was 3-60 (quartiles: 38, 46, and 51). For CDS-5, the observed range was 1-25 (quartiles: 15, 18, and 20).

Internal consistency was higher for both CDS-12 $(\alpha=0.90)$ and CDS-5 $(\alpha=0.84)$ than for FTND $(\alpha=0.66)$. Item-scale correlations were all $>0.5$, except for the items 'I smoke in spite of the risks for my health' and 'I smoke too much', but these items were nevertheless retained in CDS-12 to preserve content validity and because of their good performance on other validity tests (Table 2 ).

\section{Retest}

The retest survey was answered by 772 people, but testretest analyses were restricted to 578 participants (19\% of 3009) who were still current smokers at retest and who answered 15-31 days after the baseline survey (median interval between baseline and retest $=18$ days). Test-retest correlations were $\geqslant 0.60$ for all items, and $\geqslant 0.83$ for both CDS-12 and CDS-5 (Table 2). Test-retest correlation coefficients were significantly higher for CDS-12 than for FTND $(z=24.9, p<0.001)$, and they were also significantly higher for CDS-5 than for FTND $(z=3.73, p<0.001)$.

\section{Tests of Construct Validity}

Daily smokers had higher scores than occasional smokers for all dependence items and scales. Expressed in terms of standard deviation (SD) units, the differences between daily and occasional smokers were of 1.3SD for CDS-12 and CDS5, and 1.0SD for FTND. All items and scales were associated with a 0-100 rating of the strength of the urge to smoke during the last quit attempt. This association was stronger for CDS-12 $\left(R^{2}=0.25\right)$ and CDS-5 $\left(R^{2}=0.29\right)$ than for FTND $\left(R^{2}=0.18\right)$. Finally, all items were associated with the number of cigarettes smoked per day.

\section{Cotinine}

Saliva samples were returned by 116 people (39\% of 300 to whom salivettes were sent). Four vials contained an insufficient quantity of saliva for analysis, six vials were returned by ex-smokers, and one participant did not give valid answers to the questionnaire. The analysis was performed on the remaining 105 samples.

Compared to the rest of the sample, participants included in the cotinine analysis were 5 years older ( 37 years in the cotinine group $v s 32$ years in the no-cotinine group, $p<0.001)$ and were more likely to be men (59 vs $47 \%$, $p=0.02)$, but they were as likely to have made a 24 -h quit attempt in the previous year (52 vs $48 \%, p=0.4$ ) and they had similar levels of dependence (mean FTND $=4.3$ in both groups, $p=0.9$; mean CDS- $12=46$ in the cotinine group $v s$ 44 in the no-cotinine group, $p=0.08$ ).

All items and scales were associated with the level of saliva cotinine. CDS-5 and FTND were more strongly associated with cotinine $\left(R^{2}=0.21\right.$ for both scores $)$ than CDS-12 $\left(R^{2}=0.17\right)$.

\section{Sensitivity to Change}

For all items and scales, there was a statistically significant difference in change over time in dependence scores between those who switched from daily to occasional smoking between baseline and retest and those who remained daily smokers. Expressed in terms of SD units of these scales, the between-group difference was 1.1SD for CDS-12 and CDS-5, and 0.4SD for FTND.

\section{Cessation at Follow-Up}

The follow-up e-mail on smoking abstinence was answered by 990 people (33\% of 3009). The median interval between baseline and follow-up was 45 days, and $13 \%$ of participants in this analysis (129 of 990) had not smoked in the 7 days before the follow-up survey. None of the intended measures of dependence was a statistically significant predictor of smoking cessation.

The best predictors of smoking cessation were the selfperceived likelihood of being abstinent 1 year later $(26 \%$ of those who answered 'Very likely' had quit smoking, $v s 0 \%$ of those who answered 'Not at all likely', $p<0.001$ ), the self- 
perceived chances of success of quit attempts $(20 \%$ of those who answered 'Every chance' had quit, vs $0 \%$ of those who answered 'No chance', $p<0.001$ ), and the level of motivation to quit ( $3 \%$ quitters among smokers who had no intention to quit in the next 6 months, $7 \%$ among those who seriously considered quitting in the next 6 months, and $25 \%$ among those who had decided to quit in the next 30 days). One-third (33\%) of those who had decided to quit in the next 30 days and said that they would have 'every chance' to succeed if they tried to quit had quit smoking at 45-day follow-up.

\section{Age}

Smokers aged 12-19 had lower scores than older smokers on CDS-12 ( -7.7 points or 0.76 SD units, $p<0.001)$, CDS-5 $(-3.3$ points or $0.77 \mathrm{SD}$ units, $p=0.004)$ and FTND $(-1.2$ points or $0.50 \mathrm{SD}$ units, $p<0.001)$. Otherwise, the characteristics of CDS-5 and CDS-12 were maintained in teenage smokers (Table 6). In particular, in smokers aged 12-19, both scales produced few missing and 'Don't know' values, had test-retest correlations $\geqslant 0.77$, were significantly lower in occasional smokers than in daily smokers, were associated with cigarette/day, FTND and craving, and both scores decreased in smokers who switched from daily to occasional smoking between baseline and follow-up. However, the strength of most of these associations was significantly smaller in smokers aged 12-19 than in adult smokers (Table 6).

\section{DISCUSSION}

This paper reports on the development and assessment of the validity of a scale measuring addiction to cigarettes in daily and occasional cigarette smokers. We developed two versions of this scale: a 12 -item version, CDS-12, which covers all the main elements of DSM-IV and ICD-10 definitions of dependence, except tolerance, and a 5-item version, CDS-5, for use in situations where a shorter questionnaire is preferable. Both scales performed well on tests of construct validity, were reliable in test-retest procedures, had a high internal consistency, and were sensitive to change over time.

\section{Dimensions in CDS-12}

Factor analyses indicated that only one dimension was present in the data. At first sight, this result may seem incompatible with DSM-IV and ICD-10, which identify a list of symptoms of tobacco dependence. However, the syndrome approach used in DSM-IV and ICD-10 does not require that symptoms of dependence should be statistically independent. On the contrary, according to these definitions, any three symptoms must be present to identify a dependent individual, which implies that these symptoms are expected to be associated. Thus, our finding of a single dimension in the dependence scale is compatible with DSMIV and ICD-10.

CDS-12 contains at least one item for each dimension of dependence, as defined in DSM-IV and ICD-10, except for tolerance. Tolerance is the need for increased amounts of tobacco to achieve desired effects, or diminished effect with continued use of the same amount of tobacco (American Psychiatric Association, 1994). Items reflecting tolerance performed poorly on validity tests. Tolerance is a dynamic concept that can probably not be detected in a crosssectional sample of regular adult smokers. Tolerance may be easier to detect in young smokers who are in the process of acquiring tobacco dependence.

An important category in qualitative data included feeling nervous, irritable, anxious, or in a bad mood when lacking cigarettes. This category reflects typical tobacco withdrawal symptoms (Hughes and Hatsukami, 1986). However, items measuring withdrawal performed poorly on validity tests and were not retained in the final scales. Possibly, these items lacked validity in this sample because most withdrawal symptoms are not present in current smokers, who smoke precisely to avoid these symptoms. Withdrawal symptoms are best assessed in smokers who attempt to quit, using other available scales (Hughes and Hatsukami, 1986; Patten and Martin, 1996; Shiffman and Jarvik, 1976; Welsch et al, 1999). In CDS-12, withdrawal is nevertheless assessed by at least two items (urge to smoke when abstaining and feeling stressed by the perspective of lacking cigarettes). Arguably, the item on time to the first cigarette of the day is also a measure of withdrawal, since blood levels of nicotine are lowest upon waking up. The most specific symptom of tobacco withdrawal is the urge to smoke. It is included among withdrawal symptoms in ICD-10 and DSM-III, but not in DSM-IV. Whether craving and urge to smoke are symptoms of tobacco withdrawal has been the subject of debate (Sayette et al, 2000), because craving levels are often high in current smokers (Hughes and Hatsukami, 1992). Even though craving is not included in the list of DSM-IV symptoms of nicotine withdrawal, DSM-IV nevertheless states that 'craving is an important element in nicotine withdrawal' (American Psychiatric Association, 1994, p 245).

The self-reported $0-100$ rating of dependence performed well on tests of validity. Similar questions were identified as useful indicators of dependence on tobacco (DiFranza et al, 2002; Kawakami et al, 1999), alcohol (Spak and Hallstrom, 1996), and illicit drug use in adolescents (Latimer et al, 1997).

\section{Comparison with the FTND}

Both CDS-12 and CDS-5 were better than FTND at differentiating between daily and occasional smokers. They were more strongly associated with the strength of craving during the last quit attempt and with age, they had a higher test-retest reliability and a higher internal consistency, and CDS-5 was as strongly associated with saliva cotinine. Both scales were more sensitive than FTND to change over time, probably because the 'Yes-No' response options in FTND capture less variance in change over time than response options in CDS-12 and CDS-5. More importantly, FTND does not cover important aspects of dependence, as defined in DSM-IV and ICD-10, such as desire or efforts to quit smoking, withdrawal symptoms, time spent using tobacco, taking more tobacco than intended, and reduction of activities because of tobacco use (Etter et al, 1999). In addition, there is little agreement between FTND- and DSMbased measures of dependence (Moolchan et al, 2002). 
Table 6 Comparison of CDS-12 and CDS-5 in Adult and Teenage Smokers

\begin{tabular}{|c|c|c|c|c|c|c|c|c|c|c|c|c|}
\hline & $\begin{array}{l}\text { Missing+ } \\
\text { Don't } \\
\text { know/Not } \\
\text { applicable } \\
\text { (\%) }\end{array}$ & $\begin{array}{l}\text { Percent } \\
\text { at lowest } \\
\text { possible } \\
\text { value (\%) }\end{array}$ & $\begin{array}{l}\text { Percent } \\
\text { at highest } \\
\text { possible } \\
\text { value (\%) }\end{array}$ & Mean & SD & $\begin{array}{l}\text { Test-retest } \\
\text { correlation }\end{array}$ & $\begin{array}{l}\text { Daily- } \\
\text { occasional } \\
\text { smokers } \\
\text { b }\end{array}$ & $\begin{array}{l}\text { Cotinine } \\
(\text { ng/ml) } \\
\text { b }\end{array}$ & $\begin{array}{l}\text { Cigarettes/ } \\
\text { day } \\
\text { c }\end{array}$ & $\begin{array}{l}\text { Craving } \\
0-100 \\
\text { c }\end{array}$ & $\begin{array}{l}\text { FTND } \\
\text { c }\end{array}$ & $\begin{array}{l}\text { Switched } \\
\text { from daily } \\
\text { to occasional } \\
\text { vs daily } \\
\text { smokers } \\
\text { d }\end{array}$ \\
\hline $\begin{array}{l}\text { CDS- } 12 \text { in smokers } \\
\text { aged } 12-19\end{array}$ & 1.3 & 0.3 & 0.3 & 36.9 & 11.1 & $0.79 * * *$ & $10.3 * * *$ & $6 * * *$ & $0.4 * * *$ & $1.0 * * * *$ & $0.1 * * *$ & $-7.1 * * * *$ \\
\hline $\begin{array}{l}\text { CDS-12 in smokers } \\
\text { aged } 20-74\end{array}$ & 0.4 & 0 & 0.3 & 44.6 & 9.7 & $0.83 * * * *$ & $12.2 * * * *$ & $6 * * *$ & $0.7 * * *$ & $1.3 * * * *$ & $0.2 * * *$ & $-12.4 * * *$ \\
\hline $\begin{array}{l}\text { CDS- } 5 \text { in smokers } \\
\text { aged } 12-19\end{array}$ & 3.0 & 0.3 & 0.3 & 14.3 & 4.5 & 0.77 ****** & $4.2 * * * *$ & $8 \mathrm{~ns}$ & $1.1 * * * *$ & $2.8 * * * *$ & $0.4 * * *$ & $-3.5 * * * *$ \\
\hline $\begin{array}{l}\text { CDS-5 in smokers } \\
\text { aged } 20-74\end{array}$ & 1.3 & 0 & 0.3 & 17.6 & 4.1 & $0.83 * * * *$ & $5.6 * * * *$ & $15 * * * *$ & $1.8 * * * *$ & $3.2 * * * *$ & $0.5 * * *$ & $-5.2 * * *$ \\
\hline $\begin{array}{l}\text { p-value on diff. between } \\
\text { age groups in characteristics } \\
\text { of CDS- } 12\end{array}$ & - & - & - & $<0.001 \mathrm{e}$ & - & f & $<0.001 \mathrm{~g}$ & $0.75 \mathrm{~g}$ & $<0.001 \mathrm{~g}$ & $<0.001 \mathrm{gg}$ & $<0.00 \mathrm{lg}$ & $<0.001 \mathrm{gg}$ \\
\hline $\begin{array}{l}\text { p-value on diff, between } \\
\text { age groups in characteristics } \\
\text { of CDS-5 }\end{array}$ & - & - & - & $0.004 e$ & - & f & $<0.00 \lg$ & $0.84 \mathrm{~g}$ & $<0.00 \lg$ & $<0.001 \mathrm{~g}$ & $<0.00 \lg$ & $<0.001 \mathrm{~g}$ \\
\hline
\end{tabular}


Age

One in 10 participants was 19 years old or younger. Cigarette dependence scores were lower in these participants than in older smokers, which is compatible with previous research (McNeill et al, 1989). CDS-12 and CDS-5 performed adequately in teenage smokers, which suggests that these scales are useful indicators of dependence in young smokers. However, the strength of most associations between these scales and external variables was smaller in smokers aged 12-19 than in adult smokers, probably because younger smokers had lower dependence scores at baseline. A formal comparison with other dependence scales specifically intended for adolescents (DiFranza et al, 2002; Prokhorov et al, 2000) should be conducted before CDS-12 and CDS-5 can be recommended for use in adolescents.

\section{Study Limitations}

This study was conducted in a self-selected sample of internet users. Compared to a representative sample of smokers in Geneva, participants in this study were more motivated to quit smoking, more likely to have made a quit attempt in the previous year, and more dependent on tobacco (Etter et al, 1997). In a previous study, we compared smokers self-recruited on the same website to smokers recruited in a mail survey (Etter and Perneger, 2001c). The latter study showed that even though the distribution of smoking-related variables was different in the two samples, the strength of associations between smoking-related variables was similar in smokers recruited on the internet or by mail. Thus the present study, which focused on associations between indicators of dependence, should be generalizable. However, tests of CDS-12 and CDS5 in representative samples of smokers are warranted.

None of the measures of dependence predicted smoking cessation, but motivation to quit smoking, the selfperceived likelihood of quitting smoking, and the selfperceived chances of success of quit attempts did. Similar results were also observed by other researchers (Sciamanna et al, 2000). It is possible that the follow-up interval (45 days) was too short in this study to detect an effect of dependence on abstinence, or that too few people tried to quit between baseline and follow-up. Even though other indicators of dependence predicted smoking cessation in previous reports, this association was weak (Farkas et al, 1996; Kozlowski et al, 1994). This suggests that smoking cessation relies on psychological and social processes that are fairly independent of the level of addiction (Prochaska et al, 1992).

CDS-12 has demonstrable content validity, but it does not include a measure of tolerance. However, the utility of tolerance as a criterion for defining dependence has been questioned (Perkins et al, 2001).

Saliva samples were obtained from a subsample of participants only, and this subsample included more men and slightly older people. However, the dependence level was the same in participants who provided a saliva sample and in those who did not. While selection bias may have affected our analysis, the comparability of the samples is reassuring in this regard.
In this study, we conducted a limited number of validation tests. More tests of validity should be conducted in various samples before the validity of CDS- 12 and CDS- 5 is fully established. Such tests could include the long-term prediction of smoking cessation and relapse, the prediction of the strength of tobacco withdrawal symptoms, and tests of whether these scales are associated with increasing tolerance in longitudinal studies of young smokers. In addition, CDS- 12 and CDS-5 should be compared with available measures of dependence along several criteria, including agreement with DSM-based diagnostic interviews, as in the study by Moolchan et al (2002).

We conclude that CDS-12 and CDS-5 are reliable measures of cigarette dependence that fulfill criteria of content validity and construct validity and are sensitive to change over time. These scales should be useful both for research on addiction to cigarettes and for clinical interventions among smokers.

\section{ACKNOWLEDGEMENTS}

This study was supported by grants from the Swiss National Science Foundation to J-F Etter (3233-054994.98 and 3200055141.98). Vincent Baujard, from the HON Foundation (www.hon.ch), developed the software for data collection.

\section{COMPETING INTERESTS}

JFE was reimbursed by Pharmacia Inc., a producer of nicotine replacement products, for attending international conferences, and was paid by Novartis to give lectures on smoking cessation. The Institute of Social and Preventive Medicine at the University of Geneva received financial support from Novartis to develop an education program for users of nicotine replacement products. JLH works with Pharmacia In.

\section{REFERENCES}

American Psychiatric Association (1994). Diagnostic and Statistical Manual of Mental Disorders - Fourth Edition (DSM-IV). American Psychiatric Association: Washington DC.

Colby SM, Tiffany ST, Shiffman S, Niaura RS (2000). Measuring nicotine dependence among youth: a review of available approaches and instruments. Drug Alcohol Depend 59(Suppl 1): S23-S39.

Covey LS, Elmer L (1999). The structure and validity of the DSMIV criteria for nicotine dependence (Abstract). Nicotine Tobacco Res 1: 190.

Dawson-Saunders B, Trapp RG (1994). Basic and Clinical Biostatistics. Appleton \& Lange: Norwalk, CT, p 165.

DiFranza JR, Savageau JA, Fletcher K, Ockene JK, Rigotti NA, McNeill AD et al (2002). Measuring the loss of autonomy over nicotine use in adolescents: the DANDY (Development and Assessment of Nicotine Dependence in Youths) study. Arch Pediatr Adolesc Med 56: 397-403.

Etter JF, Duc TV, Perneger TV (1999). Validity of the Fagerstrom test for nicotine dependence and of the Heaviness of Smoking Index among relatively light smokers. Addiction 94: 269-281.

Etter JF, Perneger TV (2001a). Attitudes toward nicotine replacement therapy in smokers and ex-smokers in the general public. Clin Pharmacol Ther 69: 175-183. 
Etter JF, Perneger TV (2001b). Effectiveness of a computer-tailored smoking cessation program: a randomized trial. Arch Intern Med 161: 2596-2601.

Etter JF, Perneger TV (2001c). A comparison of cigarette smokers recruited through the Internet or by mail. Int J Epidemiol 30: 521-525.

Etter JF, Perneger TV, Ronchi A (1997). Distributions of smokers by stage: international comparison and association with smoking prevalence. Prev Med 26: 580-585.

Etter JF, Vu Duc T, Perneger TV (2000). Saliva cotinine levels in smokers and nonsmokers. Am J Epidemiol 151: 251-258.

Fagerström KO (1978). Measuring degree of physical dependence to tobacco smoking with reference to individualization of treatment. Addict Behav 3: 235-241.

Farkas AJ, Pierce JP, Zhu SH, Rosbrook B, Gilpin EA, Berry C (1996). Addiction versus stages of change models in predicting smoking cessation. Addiction 91: 1271-1280.

Feyerabend C, Russell MA (1990). A rapid gas-liquid chromatographic method for the determination of cotinine and nicotine in biological fluids. J Pharm Pharmacol 42: 450-452.

Fiore MC, Bailey WC, Cohen JJ (2000). Treating Tobacco Use and Dependence. Clinical Practice Guideline. US Department of Health and Human Services: Rockville, MD, USA.

Foulds J, Bryant A, Stapleton J, Jarvis MJ, Russell MA (1994). The stability of cotinine in unfrozen saliva mailed to the laboratory (letter). Am J Public Health 84: 1182-1183.

Greeley DA, Valois RF, Bernstein DA (1992). Stability of salivary cotinine sent through the U.S. mail for verification of smoking status. Addict Behav 17: 291-296.

Heatherton TF, Kozlowski LT, Frecker RC, Fagerstrom KO (1991). The Fagerstrom Test for Nicotine Dependence: a revision of the Fagerstrom Tolerance Questionnaire. $\mathrm{Br} J$ Addict 86: 1119-1127.

Horn JL (1965). A rationale and test for the number of factors in factor analysis. Psychometrika 30: 179-185.

Hughes JR, Hatsukami DK (1986). Signs and symptoms of tobacco withdrawal. Archi Gen Psychiatry 43: 289-294.

Hughes JR, Hatsukami DK (1992). The nicotine withdrawal syndrome: a brief review and update. Int J Smoking Cessation 1: 21-26.

Jackson DN (1970). A sequential system for personality scale development. In: Spielberger CD (ed). Current Topics in Clinical and Community Psychology. Vol. 2. Academy Press: New York, pp 61-96.

Johnson EO, Breslau N, Anthony JC (1996). The latent dimensionality of DIS/DSM-III-R nicotine dependence: exploratory analyses. Addiction 91: 583-588.

Kawakami N, Takatsuka N, Inaba S, Shimizu H (1999). Development of a screening questionnaire for tobacco/nicotine dependence according to ICD-10, DSM-III-R, and DSM-IV. Addict Behav 24: 155-166.

Kozlowski LT, Porter CQ, Orleans CT, Pope MA, Heatherton T (1994). Predicting smoking cessation with self-reported measures of nicotine dependence: FTQ, FTND, and HSI. Drug Alcohol Depend 34: 211-216.

Latimer WW, Winters KC, Stinchfield RD (1997). Screening for drug abuse among adolescents in clinical and correctional settings using the problem-oriented screening instrument for teenagers. Am J Drug Alcohol Abuse 23: 79-98.

Lichtenstein E, Mermelstein RJ (1986). Some methodological cautions in the use of the Tolerance questionnaire. Addict Behav 11: 439-442.

McNeill AD, Jarvis MJ, Stapleton JA, West RJ, Bryant A (1989). Nicotine intake in young smokers: longitudinal study of saliva cotinine concentrations. Am J Public Health 79: 172-175.

Moolchan ET, Radzius A, Epstein DH, Uhl G, Gorelick DA, Cadet JL et al (2002). The Fagerstrom Test for Nicotine Dependence and the Diagnostic Interview Schedule: do they diagnose the same smokers? Addict Behav 27: 101-113.

Nezelof S, Taccoen Y, Corcos M, Girardon N, Perez-Diaz F, Bizouard $\mathrm{P}$ et al (2001). Drug use in a declared non-addicted sample and comorbidity. A survey in 860 French-speaking subjects. Ann Med Intern 152: 18-25.

Nunnally JC, Bernstein IH (1994). Psychometric Theory. 3rd ed. McGraw-Hill: New York.

O'Connor BP (2000). SPSS and SAS programs for determining the number of components using parallel analysis and velicer's MAP test. Behav Res Methods Instrum Comput 32: 396-402.

Patten CA, Martin JE (1996). Measuring tobacco withdrawal: a review of self-report questionnaires. J Subst Abuse 8: 93-113.

Perez-Stable EJ, Benowitz NL, Marin G (1995). Is serum cotinine a better measure of cigarette smoking than self-report? Prev Med 24: 171-179.

Perkins KA, Gerlach D, Broge M, Grobe JE, Sanders M, Fonte C et al (2001). Dissociation of nicotine tolerance from tobacco dependence in humans. J Pharmacol Exp Ther 296: 849-856.

Pomerleau CS, Pomerleau OF, Majchrzak MJ, Kloska DD, Malakuti R (1990). Relationship between nicotine tolerance questionnaire scores and plasma cotinine. Addict Behav 15: 73-80.

Prochaska JO, DiClemente CC, Norcross JC (1992). In search of how people change. Applications to addictive behaviors. Am Psychol 47: 1102-1114.

Prokhorov AV, De Moor C, Pallonen UE, Hudmon KS, Koehly L, $\mathrm{Hu} S$ (2000). Validation of the modified Fagerstrom tolerance questionnaire with salivary cotinine among adolescents. Addict Behav 25: 429-433.

Sayette MA, Shiffman S, Tiffany ST, Niaura RS, Martin CS, Shadel WG (2000). The measurement of drug craving. Addiction 95(Suppl 2): S189-S210.

Sciamanna CN, Hoch JS, Duke GC, Fogle MN, Ford DE (2000). Comparison of five measures of motivation to quit smoking among a sample of hospitalized smokers. J Gen Intern Med 15: $16-23$.

Shadel WG, Shiffman S, Niaura R, Nichter M, Abrams DB (2000). Current models of nicotine dependence: what is known and what is needed to advance understanding of tobacco etiology among youth. Drug Alcohol Depend 59(Suppl 1): S9-S22.

Shiffman SM, Jarvik ME (1976). Smoking withdrawal symptoms in two weeks of abstinence. Psychopharmacology (Berl) 50: 35-39.

Spak F, Hallstrom T (1996). Screening for alcohol dependence and abuse in women: description, validation, and psychometric properties of a new screening instrument, SWAG, in a population study. Alcohol Clin Exp Res 20: 723-731.

Streiner DL, Norman GR (1995). Health Measurement Scales A Practical Guide to their Development and Use. 2nd ed. Oxford University Press: Oxford.

Ustun B, Compton W, Mager D, Babor T, Baiyewu O, Chatterji S et al (1997). WHO Study on the reliability and validity of the alcohol and drug use disorder instruments: overview of methods and results. Drug Alcohol Depend 47: 161-169.

Velicer WF (1976). Determining the number of components from the matrix of partial correlations. Psychometrika 41: 321-337.

Welsch SK, Smith SS, Wetter DW, Jorenby DE, Fiore MC, Baker TB (1999). Development and validation of the Wisconsin Smoking Withdrawal Scale. Exp Clin Psychopharmacol 7: 354-361.

World Health Organization (1992). The ICD-10: Classification of Mental and Behavioural Disorders: Clinical Descriptions and Diagnostic Guidelines. World Health Organization: Geneva.

World Health Organization (1996). Guidelines for Controlling and Monitoring the Tobacco Epidemic. World Health Organization: Geneva.

Wright JG, Feinstein AR (1992). A comparative contrast of clinimetric and psychometric methods for constructing indexes and rating scales. J Clin Epidemiol 45: 1201-1218. 